Vol. 2 No. 2- August 2021

E-ISSN: 2722-0842 | P-ISSN: $\underline{2721-8309}$

Available online at

Kementerian PPN/

\title{
A Paradigm Shift: Redesigning Public Health Resilience to Sustain National Economic Revival
}

\author{
Muhammad Andrian Senoputra \\ Budgeting and Financing Plan Division DKI Jakarta Provincial Health Office, Indonesia \\ an2.drii@gmail.com
}

\section{Introduction}

As one of the largest countries in Southeast Asia, Indonesia has shown promising economic growth since it rose from the financial crisis at the end of the 90s. Prior to the COVID-19 pandemic, Indonesia was gradually able to perform consistent economic growth and recently achieved the status of an upper-middle-income country (World Bank, 2021). Indonesia's economic growth increased during the 2010-2018 periods. The value of Gross Domestic Product (GDP) has increased from IDR 6.864 trillion (2010) to IDR 10.425 trillion (2018). Despite the slow growth in 2012-2015, Indonesia's GDP growth rate (calculated at constant prices) from 2015-2018 was relatively stable, and its GDP growth is forecasted to increase to 5.5\% in 2020 (World Bank, 2021).

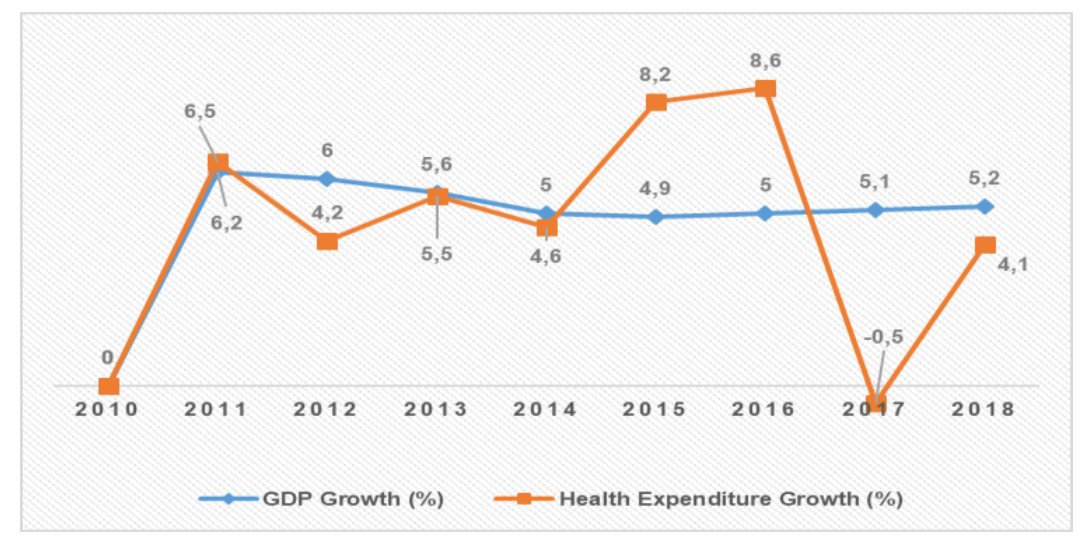

Figure 1. Indonesia's GDP and Health Expenditure Growth, 2010-2018 Source: Indonesia's National Health Account 2018, GDP Growth (annual \%) The World Bank

\begin{tabular}{|c|c|c|}
\hline $\begin{array}{l}\text { Received: July 21, } 2021 \\
\text { Received in revised form: August } \\
04,2021 \\
\text { Accepted: August,13, } 2021\end{array}$ & $\begin{array}{l}\text { JISDeP - The Journal of Indonesia } \\
\text { Sustainable Development Planning } \\
\text { Published by Centre for Planners' } \\
\text { Development, Education, and Training } \\
\text { (Pusbindiklatren), } \\
\text { Ministry of National Development } \\
\text { Planning/ National Development } \\
\text { Planning Agency (Bappenas), Republic } \\
\text { of Indonesia }\end{array}$ & $\begin{array}{l}\text { Address: Jalan Proklamasi 70, } \\
\text { Central Jakarta, Indonesia 10320 } \\
\text { Phone: +62 } 2131928280 / 31928285 \\
\text { Fax: }+622131928281 \\
\text { E-mail: } \\
\text { journal.pusbindiklatren@bappenas.go.id } \\
\text { Supported by Indonesian Development Planners } \\
\text { Association (PPPI) }\end{array}$ \\
\hline
\end{tabular}


However, the growth did not occur when the pandemic plunged the economy into a severe depression of -5.32 percent in the second quarter of 2020 (Badan Pusat Statistik, 2020). There have been serious economic disruptions in all sectors ever since. The main economic consequences not only had a direct impact, such as an increase in death, illness, and care, but influenced economic productivity, with job losses, declining in earnings, and a decrease in purchasing power for products and services. As an epidemic event, the COVID-19 pandemic has recently demonstrated the need for public health resilience carrying capacity in ensuring economic growth. Both economy and health have a strong and beneficial interdependent relationship. For many years, health services were regarded as inevitable expenses that had to be accommodated as a necessary service. However, they have recently been put at the top of the list of policy objectives. Indonesia's economic growth is not constantly in line with the growth rate of spending on goods and services in the health sector, which tends to fluctuate, ending at 4,1\% in 2018 (Figure 1). Indonesia's total health expenditure has increased from IDR 204.7 trillion (2010) to IDR 320.0 trillion (2017). Indonesia's annual per capita health expenditure has also increased from IDR 858 thousand (2010) to IDR 1.2 million (2018) at constant prices. Nevertheless, the contribution of health expenditure to the total consumption of goods and services in Indonesia stagnates only around 3\% during 2010-2018 (World Bank, 2021).

One of the most prominent economists of the modern period, William Baumol, characterized healthcare as a "cost illness" in which expenses inevitably climb. Healthcare expenses surpass the value of services given and make it less attractive than the manufacturing sector, which is viewed as a propelling engine for economic progress. Indonesia's total health expenditure is relatively low compared to several countries in Southeast Asia. Most countries in the Southeast Asia region have a higher proportion of health expenditure to GDP than Indonesia, except Laos and Brunei Darussalam (Figure 2)(WHO, 2021).

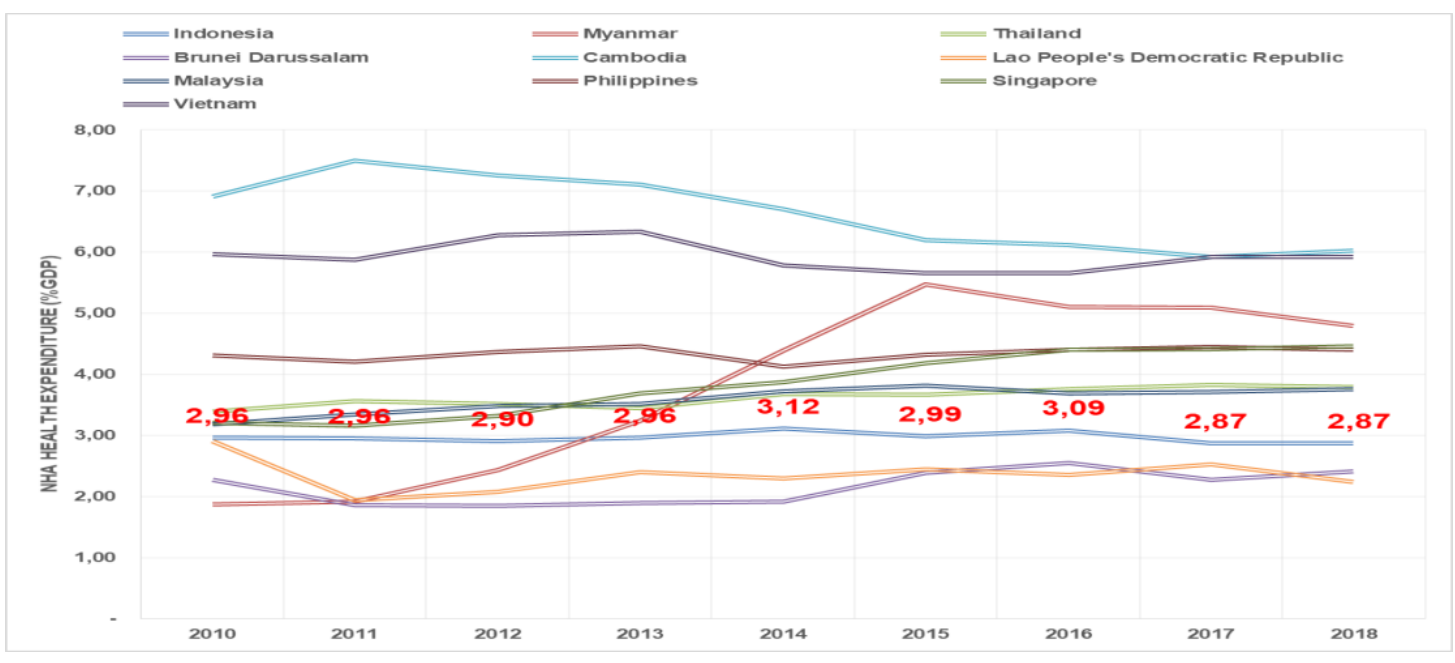

Figure 2. Health Expenditure Proportion (\%GDP) among Southeast Asia Nations Source: Global Health Expenditure Database (WHO)

The present financial structure and health care organization in many developing nations, including Indonesia, give significant incentives to treat sickness rather than invest in prevention. Since Indonesia's National Health Insurance (NHI), known as Jaminan Kesehatan Nasional (JKN), was implemented in 2014, health financing focus has been biased towards curative efforts, in which spending on health promotion and prevention interventions is marginalized (Bappenas, 2019b). Indonesia's health spending for individual healthcare reached $73,3 \%$ compared to Public Health spending $(9,6 \%)$ and Health System Management (16,8\%). See Figure 3. On the other hand, all types of health disorders require treatment interventions, including promotive and preventive interventions. Meanwhile, the current pattern and the development of health problems increase the importance of intervention in public health services and strengthen the health system (Bappenas, 2019b). If public health interventions are neglected, various targets for improving health indicators will be difficult to achieve. Although $\mathrm{NHI}$ is important, it is not the only urgent issue; the public health budgeting scheme should be considered strategic to build National health security by strengthening public health resilience. A reformed system should be integrated between personal or therapeutic care and public health approach, including 
population-wide health initiatives (Figure 3).

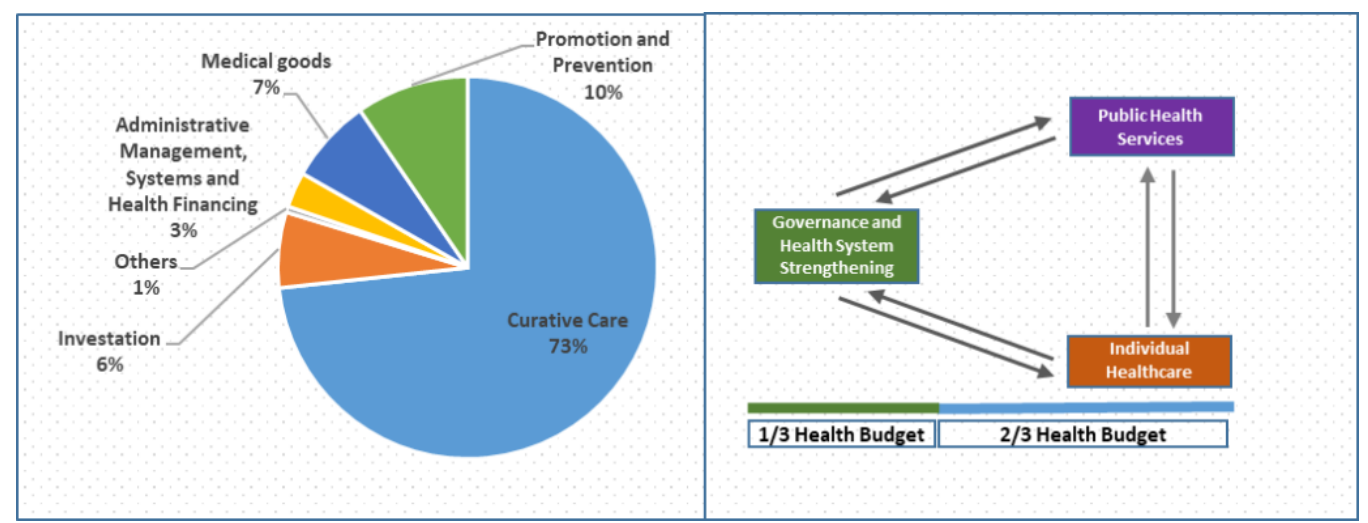

Figure 3. Public Sectors Health Expenditure and Health Budget Allocation Scheme Source: Bappenas Health Sector Review (Health Financing and National Health Insurance)

As the front line of defense against the pandemic threat, public health functions are critical parts of health systems resilience. A global health risk framework is built on strong public health competencies and infrastructure at the country level. We understand that public health cannot be viewed as a "box" (Commission on a Global Health Risk Framework for the Future \& National Academy of Medicine, Secretariat, 2016). Public health functions have a direct and critical role in enhancing the capacity to respond swiftly and efficiently to communicable diseases outbreak, including disease detection, identification, and early treatment of infected individuals (Figure 4). They are also crucial in reducing the health effects of other health emergencies, such as natural calamities and man-made disasters (Meyer et al., 2020).

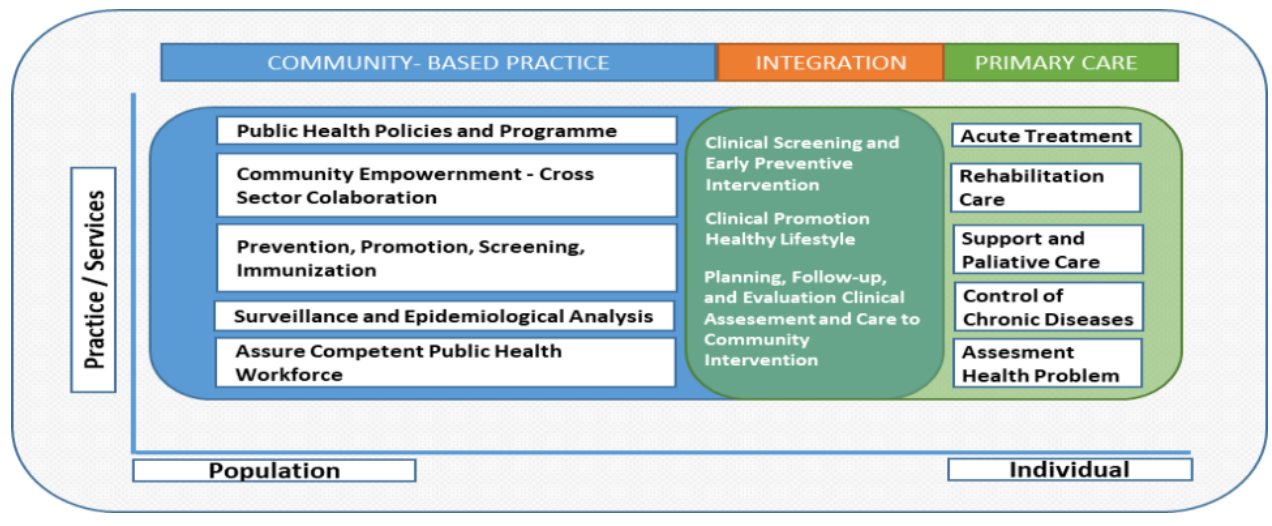

Figure 4. Intercorrelations between Public Health and Primary Care Source: Modified by Author from Public Health and Primary Care Interaction Framework

How important public health resilience is simply described from recent infectious disease outbreaks. COVID-19 pandemic shows that the world health system is not strong enough in dealing with public health disasters, where the functions of health promotion and health prevention again - for several times - fail to be optimally actualized in stemming outbreaks (Meyer et al., 2020). The escalation of COVID19 cases and hospital bed occupancy during the COVID-19 pandemic is in line with increasing population mobility and community compliance with health protocols. By June 13, 2021, Indonesia reached the highest peak number of new and active cases for the second time in the same year at 55.320 cases $(38,3 \%)$ and 113.388 cases $(15,17 \%)$, respectively (Satgas COVID-19, 2021a). The situation escalated the bed occupancy rate, reaching $80 \%$ on average and surpassing WHO recommendation of $60 \%$ (Figure 5) (Satgas COVID-19, 2021b). 

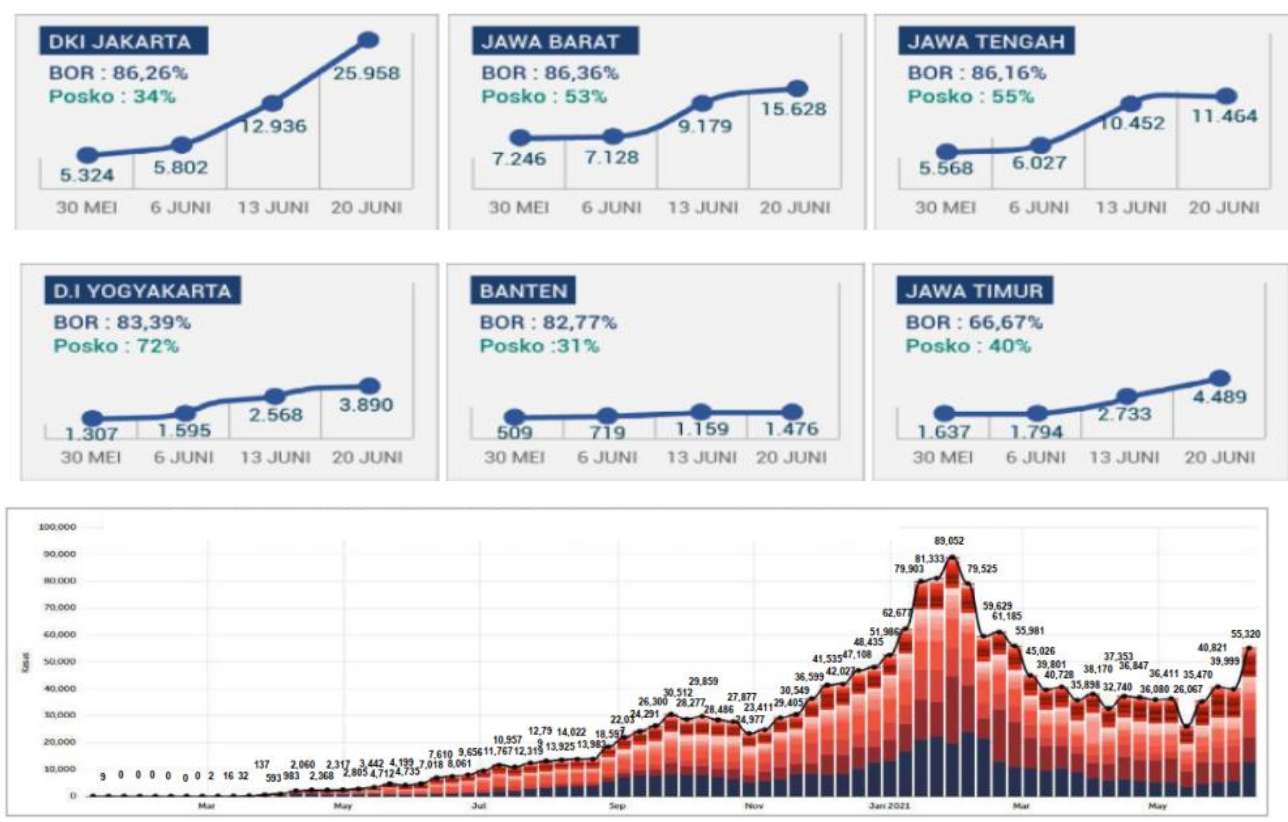

Figure 5. Bed Occupancy Rate (BOR) and COVID-19 Cases Escalation

Source: Indonesia's COVID-19 Task Force

Even though the government has strengthened the regulation, synergy among the community, government, private sectors, and other parties are required to prevent and control the spread of COVID19. Also, increasing public health function capacity to contribute as the first and secondary level prevention in containing and breaking the chain of COVID-19 spread is as important as upgrading the capacities of infirmary services to create forceful public health security. Therefore, it is necessary to build up the capacity and capability of the health system by putting public health security as a fundamental concept and priority to be upgraded (Figure 6) (Meyer et al., 2020).

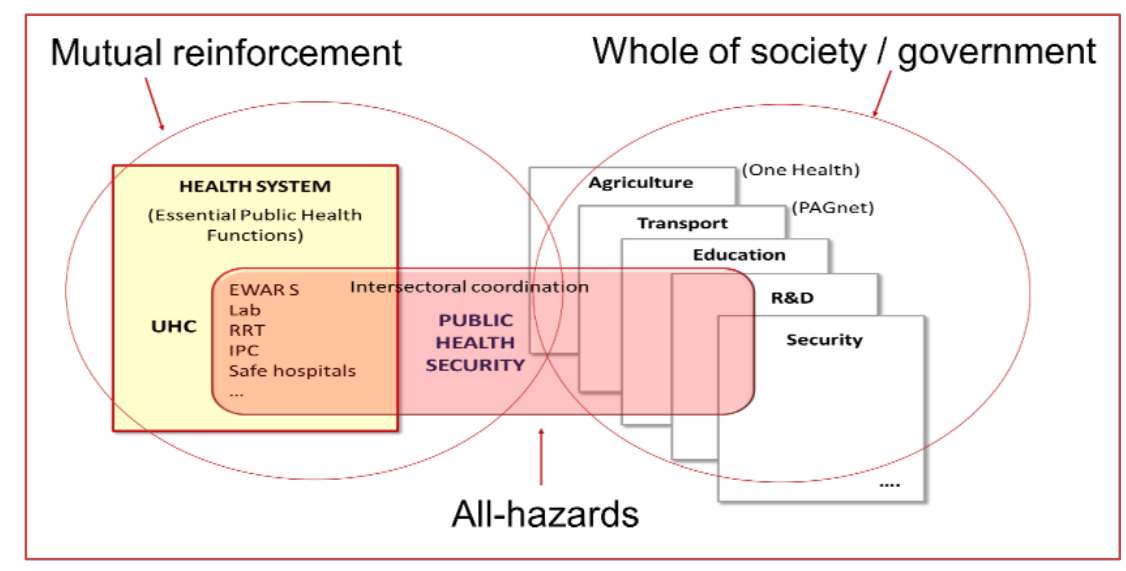

Figure 6. Emergency Preparedness Framework

Source: WHO Emergency Preparedness Framework HSS for SDGs Framework

\section{Improving priority elements for public health resilience}

In order to reinforce and advance public health across WHO regions, all members agreed to apply the International Health Regulation (IHR) through Joint External Evaluation (JEE) tool at the country level to advance health security. The Global Health Security Index (GHI) is the first thorough evaluation and comparability of health security and related capabilities among the 195 nations representing the International Health Regulations States Parties. The predictors and questionnaires prioritize interpretation of health security capacities and capabilities in the context of a state's broader national 
health system and other national health determinants to prevent, detect, and respond to biological risks and infectious disease threats that can lead to potential outbreaks. As a result, Indonesia's GHS Index is in the 'middle' category as a more prepared country, with an overall score of 56,6 above the average world score of 40,2 and ranked $30^{\text {th }}$ out of 195 countries. Nevertheless, Indonesia still has the lowest index score for some elements which need to be upgraded as fundamental functions to detect and respond, such as real-time surveillance and reporting, emergency planning and response, and public health vulnerabilities (NTI, JHU, \& EIU, 2019). Four concepts can be considered to improve the performance of these elements, including:

\subsection{Integrated Surveillance System}

Public health surveillance is the continual comprehensive collection, analysis, and interpretation of data, which is strongly linked to the timely distribution of these data to those responsible for disease prevention and control (Thacker \& Berkelman, 1988). This is a method for estimating the health condition and behavior of societies. Because surveillance can directly monitor what is happening in the population, it is valuable for determining the need for interventions and the effectiveness of treatments. The goal of surveillance is to provide timely, meaningful evidence to decision-makers, allowing them to lead and manage more effectively (Jamison et al., 2006). In this scope, Indonesia has the lowest GHS Index score among other indicators responsible for supporting response capability. We need to dig deeper to develop a strong foundation and create a powerful public health real-time surveillance and integrated reporting system that serves updated epidemic-risk information and can be accessed by all levels of the health care system (Baker \& Fidler, 2006).

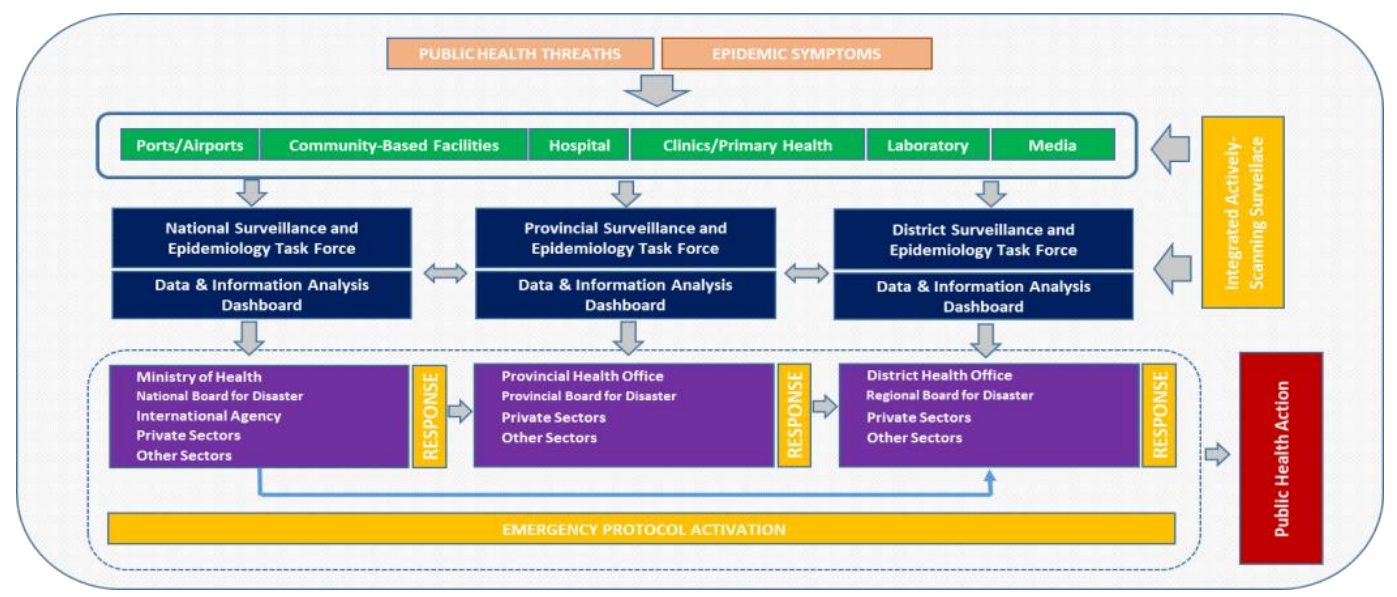

Figure 7. Integrated Disease Surveillance and Response (IDSR) Conceptual Framework Source: Modified by the author from technical guidelines for integrated disease surveillance and response (WHO, 2019)

The new Integrated Disease Surveillance (IDSR) regional model is one of the initiatives to be taken seriously as part of the overall endeavor to enhance health systems. In early 2000, Indonesia had developed a tiered "IDSR-like" surveillance system guideline, starting from the primary health center to the national level (ICDC/ADB project), yet no further progress is made (Bappenas, 2019a). The development of this information system is critical in dealing with public health security problems. The IDSR strategy links epidemiological and laboratory data at all service levels in the infectious disease surveillance system, focusing on integrating surveillance and response. This strategy is based on core activities, including case-patient detection, registration, and confirmation; reporting, analysis, and data feedback; epidemic preparedness; quick and continuous response and real-time epidemic investigation responses; public health interventions, and contact tracing (WHO, 2020).

Districts should develop powerful and strict surveillance systems through population-centered surveillance units and health services, mainly in ports, airports, and national borders. This should be prioritized to increase efforts to gather timely data, analyze the collected data, and use the information for public health actions. Furthermore, laboratory-based surveillance and virology sentinel surveillance may be carried out by utilizing clinical specimens collected by ILI, ARI, and SARI sentinel surveillance. Integrated epidemiological and viral surveillance will be critical in tracking viral transmission and 
evolution, such as comprehending viral co-circulation, interpreting respiratory epidemiology and clinical data, and supporting diagnostic tests and therapy updates. The integrated surveillance methods at all levels encourage active surveillance of emerging rumors that are continuously updated into the information system over time. The information obtained can be quickly converted into decisions in activating emergency response in all service units (Figure 7).

\subsection{Creating epidemic-agile Primary Health Center (PHC)}

Health systems continue adapting to cope with the pandemic. Much focus has been placed on the scaling-up of hospital, drug, and workforce capacities. Meanwhile, PHC are increasingly overwhelmed in stemming the growth of the pandemic, reaching a critical point towards health system failure. This COVID-19 crisis highlights the significance of community-centered health services at the foundation of health systems, both for managing an unanticipated increase in demand and ensuring continuity of service to everyone. Robust Primary Health Center (PHC), structured with cross-functional teams and health professionals, directly connected with communities, equipped with digital technology, and performed with well-designed objectives, is expected to help in delivering a successful health system response.

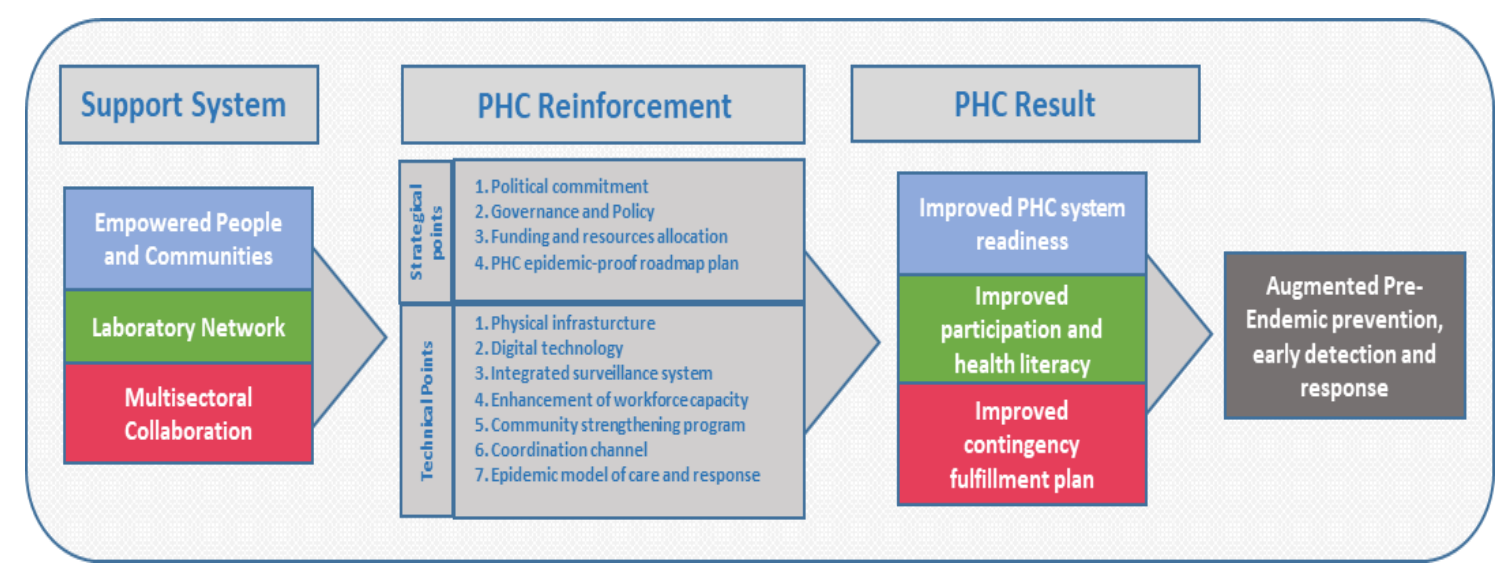

Figure 8. Epidemic-proof Primary Health Center (PHC) Conceptual Framework

Source: Modified by Author from the operational framework for primary health care: transforming vision into action

The Astana Declaration reaffirms primary care as the primary driving force behind universal health coverage. We must consider the three primary functions of addressing people's vital needs rather than simply meeting people's needs during the illness; investigating the social determinants of health problems, for example, financial difficulties and limited educational opportunities; and enabling communities to participate in the protection and enhancement of their fitness and well-being (The Lancet, 2018).

The concept of "rebuild better" was used at the Third United Nations World Conference on Disaster Risk Reduction to describe a post-disaster recovery strategy that reduces vulnerability to future disasters and builds communities' ability to respond to the challenges (Hallegatte et al., 2018). The notion of health resilience is dualistic, comprising both adaptability and robustness. Both are required and interconnected for resilience (Abimbola \& Topp, 2018). The pre-disaster setting determines the resilience of health systems. The system's initial robustness determines the adequacy of the adaptive response. For example, an adequate digital health infrastructure (system robustness) is required to expedite telemedicine delivery (an adaptive response). One fundamental aspect of building public health resilience is through institutions, facilities, and community inter-correlation reinforcement (Figure 8). Primary Health Center (PHC) has a pivotal for those transformational changes that can play both dualistic concepts and focus on sharpening immunity shield from epidemic events. Some transformations to be upgraded include:

1) Building an integrated surveillance system and facilities with individual and population-centered approaches by developing a Field Epidemiology Training Program (FETPs) from the lowest community level collaborated with private and educational institutions to expand informal 
networks

2) Increasing the capacity and capability of health workers through epidemic surveillance management and continuous responses training

3) Building a road map for strengthening epidemic-proof Primary Health Center and preparing standard operational documents and pre-endemic and pandemic action plan modules

4) Community empowerment through pre-epidemic and epidemic education, promotion, general guidelines booklet, and building communication and coordination networks at the household level

5) Increasing the portion of primary health center budgeting for pre-epidemic activities and initial response, and strengthening infrastructure and workforce capacity, health promotion, and epidemic reserve budgets

6) Developing and strengthening public health laboratory networks

7) Developing handy digital tools and telemedicine services

All these points must be developed gradually to build an integrated system that is responsive to minimize outbreaks and fatalities and to quickly respond in recognizing patterns and possible rumors of an outbreak.

\subsection{Surging Community Engagement}

The Ministry of Health created a program called "Desa Siaga" in 2006, which is a form of reorienting health services from being centralized and top-down to being more participatory. Desa Siaga is a village whose residents have resources and capabilities, readiness, and the will to independently prevent and deal with health problems, disasters, and health emergencies (Hadi, 2020). The integration between this concept and the outbreak emergency preparedness plan will strengthen community participation and empowerment at the village level. During public health emergencies, community participation and other community-centered approaches are increasingly acknowledged as crucial parts of health emergency planning and response to create favorable and intensified circumstances for behavior change, thereby reducing the spread of disease (Bedson et al., 2020). In the event of a pandemic COVID-19 outbreak, community action is critical for the public health response. Fundamentally, the transmission of the disease is slowed by the actions of community members, such as adhering to social distancing, respiratory and hand hygiene guidelines. People who are clinically susceptible and must be 'protected' by staying at home for an extended period can successfully self-isolate and reduce the exposure risk to COVID-19 only with community assistance.

Communities and community-centered groups will play a significant role in the rebuilding process. Community resilience refers to a community's ability to cope with and recover from large-scale catastrophes. One systematic review and meta-analysis assessed 35 citizen engagement programs in Lower-Middle-Income Countries (LMICs). It was found that enhanced citizen engagement occurred primarily through four routes: participation, the inclusion of marginalized groups, transparency, and literacy. Intervention targets are at the level of internal institutional systems (decentralization of and community engagement in decision-making) and external engagement with citizens (interventions to disseminate information on performance, quality, or cost) that contribute to building emergency capacity in the community (Figure 9). There are several essential points to propose in terms of this community affirmation:

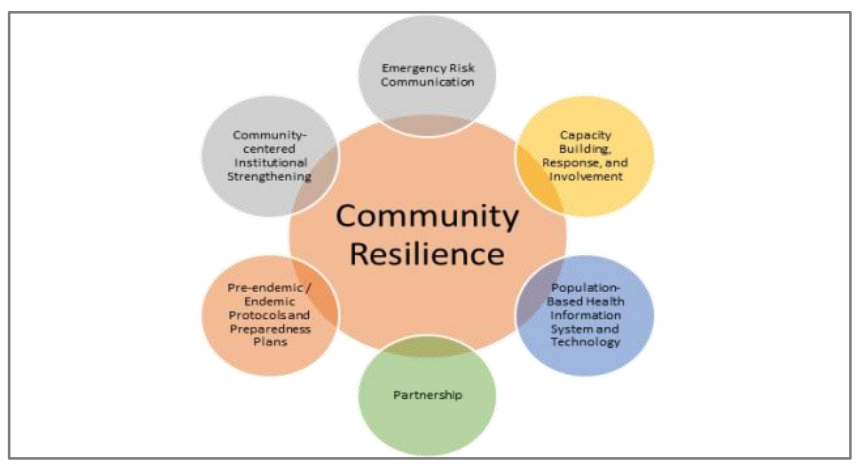

Figure 9. Community-centered public health support systems Source: Compiled by Author 
1) Community Literacy and Emergency Risk Communication

The COVID-19 pandemic has exposed the evidence that health literacy is an "overlooked worldwide public health problem." Health literacy, defined as "the degree to which individuals have the ability to collect, process, and comprehend basic health information and services required to make knowledgeable decisions," is a prerequisite for implementing healthy behaviors that can shield both infectious and non-infectious diseases. (Collins et al., 2020).

Poor hygiene habits at the individual, home, community, and corporate level are connected to low health literacy, contributing to or worsening disease outbreaks. Handwashing with soap, for example, has been identified as one of the most cost-effective health interventions for reducing disease burden. However, it is estimated that only $19 \%$ of the population washes their hands with soap after using sanitary facilities (Freeman et al., 2014). Decision-makers must assess their public health literacy requirements and engage in long-term public awareness campaigns as part of pandemic preparation and response. A continuous public communication initiative with clear and straightforward messaging helped people understand what the measures are being taken and practical advice on what individuals might do to protect their own and their families' wellbeing.

There is a need to develop an effective emergency risk communication approach, taking into account the following principles:

a) Truthful and prompt

b) Listening through two-way communication

c) Effective channels and key influencers

2) Sustainable Information Flow

The development of real-time community data collection and evaluation should be prioritized as critical inputs to support response decision-making.

3) Capacity Building and Response

Through activation of dasawisma, community leaders, RT/RW, and UKBM cadres, front-line community workers should be appropriately taught, compensated, assisted, and monitored to detect the epidemic occurrence. In addition, the existence of guidelines related to community responses and simulations of technical implementation in the field will regularly increase the readiness and public habituation in dealing with outbreaks of communicable diseases.

4) Simply applicable technology

Using handy technology and application to assist communities in monitoring citizens' health can maintain and improve the quality of community life (Lo et al., 2020). The development of user-friendly and informative applications for the community to monitor, report, and continuously communicate with mentors will increase insight and habituation for the community in receiving various information that can help the community interact, provide reinforcement and support, and cross-check the circulating information at once.

5) Population-based asset preparedness

Mapping and mitigating facilities and capacities readiness sourced from community assets can be an important support in building community-centered preparedness. This effort is necessary to anticipate and respond quickly in the initial phase of an outbreak and monitor the development of events that are suspected of developing into outbreaks.

6) Community Involvement

This approach can be performed by stimulating the local community, including marginalized groups, to join in developing participation plans. This initiative must be embraced by the government and non-government institutions to enable community independence and economic resilience.

7) Workforces, NGOs, and Community Partnership

Establishing partnerships among community residents, health care experts, and epidemicprevention professionals can develop community-centered clinics for triage and treatment. Moreover, utilizing voluntary and community sector (VCS) organizations can be important, particularly the grassroots organizations in touch with groups and individuals who face the greatest risks and underserved populations.

Building resilient communities and supportive settings have long been highlighted as a public health concern by the WHO Regional Office for Europe. Creating resilient communities is about what public health systems can do to improve protective characteristics, such as strong social networks, to 
help people and communities organize, respond, and recover successfully (South et al., 2020).

\subsection{Investing in preparedness}

It has been predicted using some models that the annual cost of a global influenza pandemic would impact South Asia's GDP to contract by $2 \%$ (World Bank, 2021). Indonesia's first COVID-19 episode was reported in March 2020, with GDP growth for the first quarter of 2020 falling from 5\% to 3\%, compared to the typical average year-on-year (YoY). This was followed by contractions to $-5.3 \%$ in the second quarter and $-3.5 \%$ in the third quarter, bringing the total growth of $-2.0 \%$ at the end of 2020 (YoY) (Habir \& Wardana, 2020). This experience demonstrated how much economic loss had suffered due to unpreparedness in the prevention of a pandemic like COVID-19. The world has witnessed several examples of what former World Bank President Jim Kim has described as a cycle of "panic, neglect, panic, neglect." The fear caused by a disease epidemic recedes, attention changes and our essential outbreakfighting systems shift to fade.

Despite years of legislative debate, convincing economic analyses, and technically feasible alternatives prior to COVID-19, national investments in pandemic preparedness were "woefully inadequate." Based on Pandemic Preparedness Financing Report released by WHO, Indonesia is categorized as "developed capacity" where annual per capita cost to implement NAPHS, and IHR core capabilities are estimated only 0,03\% of total health expenditure, lower than Myanmar and Vietnam with $0,84 \%$ and $0,26 \%$ respectively (World Bank, 2019). For decades, this percentage depicts that several worldwide societies underinvest in readiness and interrupted funding for the reaction when the outbreak struck, claiming millions of deaths and billions of dollars in national income.

World Bank and WHO analysts predict that investments in health systems to implement IHR (2005) will lead to positive returns and a high level of outbreak preparedness. According to the World Bank and WHO approximation, most nations would need to invest between USD 1 and USD 5 per person per year to achieve an adequate level of pandemic preparation. An annual investment of USD 1.9-3.4 billion in health systems would result in an estimated worldwide public benefit of more than USD 30 billion per year, up to 10 times greater investment return (Global Preparedness Monitoring Board, 2019). We realize this is a rough estimation with a wide error margin. However, the change of investment perspective can continue to evolve as a new transformational approach which would help suppress the estimated cost will be even more significant in handling outbreaks in the future.

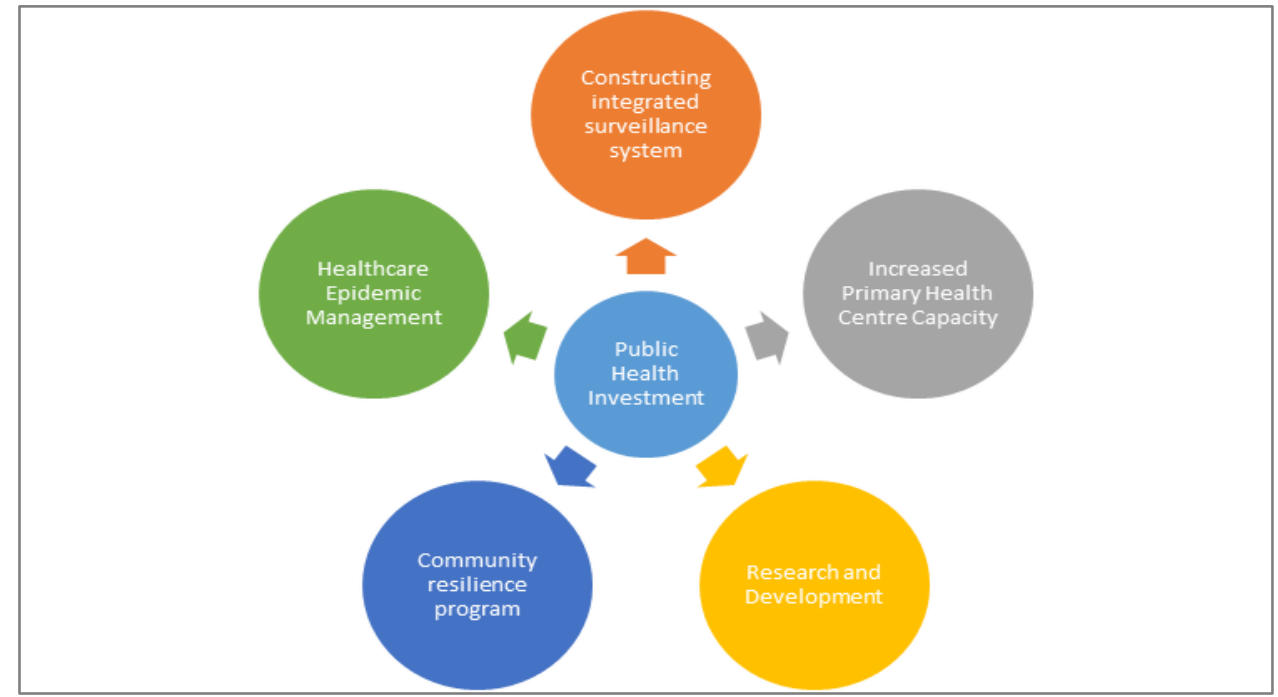

Figure 10. Public Health Investment Scheme Source: Compiled by Author

From this perspective, it makes sense to consider making a contingency financing framework, build National preparedness capacities by referring to International Health Regulation (IHR), and ensure rapid and effective preventive strategies that can be invested in some ways (Figure 10). There are many concepts proposed on how to enhance health structure resilience. A better system could be based on the principle of active preparation and should be built on mechanisms that can be applied consistently, 
dynamically, and "Stay Sync." As a result, they are ready to-work when outbreaks occur. There are three public health pillars that can be considered to invest in, which have a pivotal role in responses since the first occurrence of rumors performing the tendency for becoming an outbreak.

1) Investing in constructing an actively scanning surveillance system

The idea of an active surveillance system may encourage governments and other stakeholders to figure out how to improve this tool. We can identify how to address gaps in this system in order to respond promptly and effectively to pandemic occurrences. Through preestablished coordination channels among public and private sectors, and the community, the investment can be considered to be allocated to develop these points:

a) Building effective rumor-based screening system at the point of entry;

b) Creating communication and coordination channel: risk communication systems, internal and sectoral communication and coordination, effective communication and community involvement and rumor management;

c) Conduct regular outbreak simulations and cross-sectoral preparedness activities;

d) Enhancing epidemiological response capacities;

e) Composing clear and applicable surveillance protocols in all levels;

f) Developing IDSR-like surveillance of noticeable diseases;

g) Developing robust pathogen surveillance and serosurveillance;

h) Building up data integration and sophisticated surveillance information system and infrastructure;

i) Establishing Population-representative surveillance task force.

2) Community-healthcare partnership

Another gap found in the early handling of pandemic events is the readiness of the health system to adapt and respond quickly through changing all sub-systems to emergency mode. In the preparatory phase, health systems can be detailed to define epidemic control plans, increase health care capacity, community-centered resources, and assets used to increase additional capacity. These include converting non-healthcare facilities to field hospitals, referring patients by implementing health protocols, redistributing medical-supply stockpiles and emergency equipment supply-chain for community workforces, and preparing communitybased quarantine and isolation facility plans. Another measure is developing community capacity-building programs with mentors from community health workers. In addition, the epidemic growth capacity plan should address the need to maintain basic health care services. Systematic joint external evaluation (JEE) tools can be used to assess the overall system readiness and determine the highest priority demand for pandemic preparedness and investment planning.

3) National Research and Development

Public health experts have often highlighted the threat posed by emerging infectious diseases. However, current national financing and incentive systems fail to recognize and promote innovations that might contribute to the fight against emerging infectious diseases. It seems the government has not been serious in developing information from the community and laboratory-based public health research into practical interventions and vaccine or drug products. Learning from the COVID-19 pandemic, there was a delay in developing specific preventions and interventions. Thus, refinement of research, capacity, and infrastructure development is needed to support national independence, rapid and specific interventions in dealing with future outbreaks. Some approaches to consider are:

a) Engaging in the research to find promising vaccines, antiviral agents, prospective antibodies, treatment formulation, and manufacturing capacities to face emerging infectious diseases and suspected substances;

b) Investigating antibiotic resistance and animal to human disease transmission threats;

c) Studying health determinants and developing specific interventions and cross-sectoral collaboration in building new habits and a healthy environment 


\section{Conclusion}

Comprehensive evaluations related to the public health function resilience are still very limited. We know that the government, along with other parties, recently remains focused on navigating the current crisis. However, establishing a readiness framework by strengthening public health functions and other public goods, accompanied by prevention-based investments, is urgently needed by enhancing the ongoing COVID-19 response and reducing the chance of future pandemics. These parallel approaches need to be applied continuously. On the one hand, it can accelerate the recovery of community health, which will synergize with economic revival. On the other hand, it will strengthen preparedness which will support sustainable national economic growth and prevent a greater economic collapse in the future caused by other communicable outbreaks.

\section{Reference}

Abimbola, S., \& Topp, S. M. (2018). Adaptation with robustness: The case for clarity on the use of 'resilience' in health systems and global health. BMJ Global Health, 3(1), e000758. https://doi.org/10.1136/bmjgh-2018-000758

Baker, M. G., \& Fidler, D. P. (2006). Global Public Health Surveillance under New International Health Regulations. Emerging Infectious Diseases, 12(7), 1058-1065. https://doi.org/10.3201/eid1207.051497

Bappenas. (2019a). Fungsi Kesehatan Masyarakat (Public Health Functions) dan Health Security. Kementerian PPN/Bappenas. https://www.bappenas.go.id/files/1115/9339/2602/Policy_Brief_Tema_2_Fungsi_KesMas_dan _Health_Security.pdf

Bappenas. (2019b). Pembiayaan Kesehatan dan JKN. Kementerian PPN/Bappenas. https://www.bappenas.go.id/files/6415/9339/2471/FA_Preview_HSR_Book10.pdf

Bedson, J., Jalloh, M. F., Pedi, D., Bah, S., Owen, K., Oniba, A., Sangarie, M., Fofanah, J. S., Jalloh, M. B., Sengeh, P., Skrip, L., Althouse, B. M., \& Hébert-Dufresne, L. (2020). Community engagement in outbreak response: Lessons from the 2014-2016 Ebola outbreak in Sierra Leone. BMJ Global Health, 5(8), e002145. https://doi.org/10.1136/bmjgh-2019-002145

BPS. (2020). Badan Pusat Statistik. https://www.bps.go.id/pressrelease/2021/02/05/1811/ekonomiindonesia-2020-turun-sebesar-2-07-persen--c-to-c-.html

Cameron, E. E., Nuzzo, J. B., \& Bell, J. A. (2019). 2019 Global Health Security Index. 324.

Collins, T., Akselrod, S., Bloomfield, A., Gamkrelidze, A., Jakab, Z., \& Placella, E. (2020). Rethinking the COVID-19 Pandemic: Back to Public Health. Annals of Global Health, 86(1), 133. https://doi.org/10.5334/aogh.3084

Commission on a Global Health Risk Framework for the Future \& National Academy of Medicine, Secretariat. (2016). The Neglected Dimension of Global Security: A Framework to Counter Infectious Disease Crises (p. 21891). National Academies Press. https://doi.org/10.17226/21891

Freeman, M. C., Stocks, M. E., Cumming, O., Jeandron, A., Higgins, J. P. T., Wolf, J., Prüss-Ustün, A., Bonjour, S., Hunter, P. R., Fewtrell, L., \& Curtis, V. (2014). Systematic review: Hygiene and health: systematic review of handwashing practices worldwide and update of health effects. Tropical Medicine \& International Health, 19(8), 906-916. https://doi.org/10.1111/tmi.12339

Habir, M. T., \& Wardana, W. (2020). COVID-19's Impact on Indonesia's Economy and Financial Markets. 2020, 13.

Hallegatte, S., Rentschler, J., \& Walsh, B. (2018). A I BUILDING BACK BETTER. 47.

Jamison, D. T., Breman, J. G., Measham, A. R., Alleyne, G., Claeson, M., Evans, D. B., Jha, P., Mills, A., \& Musgrove, P. (Eds.). (2006). Disease Control Priorities in Developing Countries (2nd ed.). World Bank. http://www.ncbi.nlm.nih.gov/books/NBK11728/

Lo, H.-W. A., Huang, J.-J., Chen, C.-C., Tsai, D., Chou, F. H.-C., \& Shieh, V. (2020). Community-Based Epidemic Prevention in Taiwan: Combating the Coronavirus Disease-2019 Crisis. Disaster Medicine and Public Health Preparedness, 14(3), e15-e16. https://doi.org/10.1017/dmp.2020.146

Meyer, D., Bishai, D., Ravi, S. J., Rashid, H., Mahmood, S. S., Toner, E., \& Nuzzo, J. B. (2020). A checklist to improve health system resilience to infectious disease outbreaks and natural hazards. BMJ Global Health, 5(8), e002429. https://doi.org/10.1136/bmjgh-2020-002429 
Satgas COVID-19. (2021a). Berita Terkini / Satgas Penanganan Covid-19. https://covid19.go.id/berita/satgas-minta-daerah-optimalisasi-ppkm-sekarang-juga

Satgas COVID-19. (2021b). Berita Terkini / Satgas Penanganan Covid-19. https://covid19.go.id/berita/analisis-data-covid-19-indonesia-update-13-juni-2021

South, J., Stansfield, J., Amlôt, R., \& Weston, D. (2020). Sustaining and strengthening community resilience throughout the COVID-19 pandemic and beyond. Perspectives in Public Health, 140(6), 305-308. https://doi.org/10.1177/1757913920949582

Suprayoga Hadi. (2020). Disaster Management in the Implementation of the 2030 Sustainable Development Goals in Indonesia. The Journal of Indonesia Sustainable Development Planning, 1(1), 105-111. https://doi.org/10.46456/jisdep.v1i1.49

Thacker, S. B., \& Berkelman, R. L. (1988). PUBLIC HEALTH SURVEILLANCE IN THE UNITED STATES. Epidemiologic Reviews, 10(1), 164-190. https://doi.org/10.1093/oxfordjournals.epirev.a036021

The Lancet. (2018). The Astana Declaration: The future of primary health care? The Lancet, 392(10156), 1369. https://doi.org/10.1016/S0140-6736(18)32478-4

WHO. (2020). Surveillance strategies for COVID-19 human infection: Interim guidance, 10 May 2020 (WHO/2019-nCoV/National_Surveillance/2020.1). World Health Organization. https://apps.who.int/iris/handle/10665/332051

WHO. (2021). Global Health Expenditure Database. https://apps.who.int/nha/database/Select/Indicators/en

WHO, \& World Bank. (2019). A World at Risk: Annual report on global preparedness for health emergencies - Global Preparedness Monitoring Board [EN/AR/RU/ZH] - World. ReliefWeb. https://reliefweb.int/report/world/world-risk-annual-report-global-preparedness-healthemergencies-global-preparedness

World Bank. (2019). Pandemic Preparedness Financing Status Update. World Bank. https://apps.who.int/gpmb/assets/thematic_papers/tr-4.pdf

World Bank. (2021). Indonesia Overview. https://www.worldbank.org/en/country/indonesia/overview 